\title{
Chitin - A Structural Polysaccharide for Health and Environmental Alimentation
}

\author{
Mohammad Azizur Rahman ${ }^{1}$, Nabidur Rahman ${ }^{1}$, Salman Shakil ${ }^{1}$, Shahdat Hossain ${ }^{2}$ \\ ${ }^{1}$ Department of Biochemistry and Molecular Biology, Jahangirnagar University, Bangladesh. \\ ${ }^{2}$ Department of Biochemistry and Molecular Biology, Prime Asia University, Bangladesh.
}

*Corresponding Author: Mohammad Azizur Rahman, Department of Biochemistry and Molecular Biology, Jahangirnagar University, Bangladesh.

Received date: August 14, 2021; Accepted date: September 29, 2021; Published date: October 28, 2021

Citation: Mohammad Azizur Rahman, Nabidur Rahman, Salman Shakil, Shahdat Hossain (2021) Chitin - A Structural Polysaccharide for Health and Environmental Alimentation. J, Biotechnology and Bioprocessing 2(8); DOI: 10.31579/2766-2314/056

Copyright: ( 2021, Mohammad Azizur Rahman, This is an open access article distributed under the Creative Commons Attribution License, which permits unrestricted use, distribution, and reproduction in any medium, provided the original work is properly cited.

\begin{abstract}
Ever increasing physiological and environmental abnormalities warrant natural, safe, easy to extract, less expensive and eco-friendly bio-components of versatile usage. Chitin, the second most abundant polysaccharide in the world, seems promising in fighting diseases, boosting immunity up and maintaining environment fresh. Chitin is a polysaccharide of $\mathrm{N}$-acetyl-D-glucosamine forms the exoskeletons of arthropods, mollusks and insects, cell walls of fungi and scales of fishes. Based on extraction, purification and integration enhancement, chitin could be of greater importance for the maintenance of human health, agriculture and environment. Present article compares and contrasts the methods utilized for extraction and purification of chitin from different sources and review its current fields and suggest the future aspects.

Keywords: chitin; chitin derivatives; chitosan; bio-medical applications of chitin; environmental usage of chitin; future aspects of chitin
\end{abstract}

\section{Introduction}

Chitin is a large, structural linear polysaccharide made from chains of $\mathrm{N}$ acetyl-D-glucosamine [2-(acetylamino)-2-deoxy-D-glucose)] [Figure 1]. It was first identified in 1811 [1]. After cellulose, chitin is the most abundant aminopolysaccharide in nature [2]. It is the building material that provides strength to the exoskeletons of crustaceans, insects, and the cell walls of fungi [2]. Chitin occurs in nature as ordered macro fibrils that can be converted to its most well-known derivative, chitosan. Chitosan is produced commercially by enzymatic or chemical deacetylation of chitin [3]. Chitin is not soluble in water, but chitosan is [3]. Based on sources, chitin has two allomorphs: $\alpha$ and $\beta$ [3]. These can be differentiated by infrared and solid-state NMR spectroscopy, together with X-ray diffraction. Chitin synthase is the key enzyme in the biosynthesis of chitin [3]. However, chitin has some excellent chemical and biological properties that open the chances to use it efficiently in different fields. The biological properties of chitin includes biocompatibility, biodegradable to normal body constituents, safe and non-toxic, haemostatic, fungistatic, antitumor and antimicrobial, spermicidal and antihypercholesterolemic [4]. This excellent biological property widens its uses in food industry, textile industry, agriculture, bioengineering, biotechnology, biomedical and pharmaceutical fields, waste water treatment, pollutant removal, cosmetics and toiletries [4]. Besides, some new aspects of chitin are also in consideration. This article reviews the already explored and probable future aspects of chitin in health and environmental alimentation. 


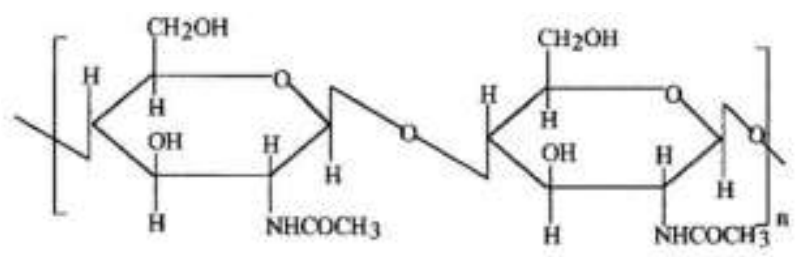

Chitin

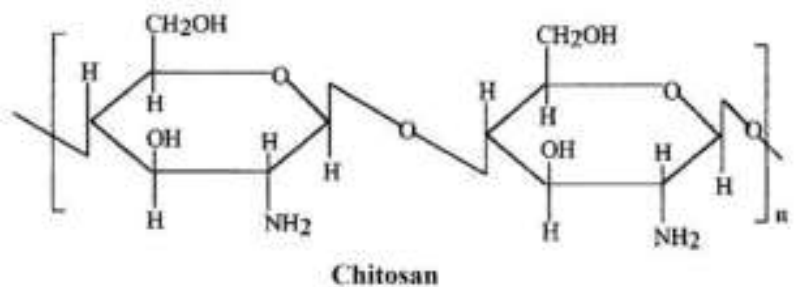

Figure 1. Structure of Chitin and Chitosan.

\section{Sources of chitin}

Chitin is found in both animal and plant kingdom [4-5]. Chitin is a crucial structural component of various marine organisms including the crustaceans, coelenterate, annelids, cnidarians and mollusks [4-5]. Although the main commercial sources of chitin are crabs and shrimps, insects serve as an alternative source of chitin, which forms up to $40 \%$ of their exoskeleton [4-5]. Insects containing chitin are ant, scorpion, brachiopod, cockroach, spider and beetle. [4-5]. Some microorganisms are also a potential source of chitin that includes fungal cell wall and mycelia, brown algae, green algae and yeast [4-5]. If it is utilized properly from its sources, it can be big boost for new applications in various new fields.

\section{Extraction of chitin}

Extraction of chitin begins with the selection of sources, especially the shells of crabs and shrimps, and ends with the cleaning; drying and grounding into tiny shell pieces [3]. This selection has major significance on the subsequent quality of the final isolated material [3]. More importantly, shells of the same size and species are needed to be chosen in case of lobsters and crabs, but the thinness of the shell wall often makes the isolation process very much simple which can be seen in case of shrimps [6]. In case of industrial and laboratory processing, chitin is extracted by acid treatment to dissolve the calcium carbonate followed by an alkaline solution to dissolve proteins [7]. Residual pigments can be removed by an extra step known as decolorization step [7]. The aim of chitin extraction is to eliminate proteins, minerals, lipids and pigments until only chitin is obtained [8]. A large number of methods have been developed and used for the preparation of pure chitin. Generally, two types of methods are utilized for the isolation of chitin: chemical and biological $[5,8]$. Sometimes, the combination of both methods makes the isolation much efficient $[5,8]$.

\subsection{Chemical extraction}

Through different chemical bonding, chitin forms "chitin-protein matrix" that becomes further calcified (mostly through deposition of calcium carbonate and calcium phosphate) in the skeletal muscles of the sources $[3,6-8]$. Chemical extraction process involves removal of proteins (deproteination, dp) and minerals (demineralization, dm) [3, 6-8]. Sometimes, removal of residual lipids (delipidation, dl) and carotenoids becomes inevitable for isolation of pure chitin.
3.1.1 Chemical deproteinization: Main concern in chemical deproteinization is the disruption of chemical bonding between chitin and protein through alkali (especially $\mathrm{NaOH}$, at $95^{\circ} \mathrm{C}$ ) treatment.

3.1.2 Chemical demineralization: Acidic treatment at high temperature is performed for chemical demineralization of chitin. Hydrochloric acid $(\mathrm{HCl})$ is the mostly used demineralizing agent for commercial production of chitin.

3.1.3 Chemical decomposition: Demineralization follows the decomposition of the calcium carbonate into the water soluble calcium salts with the release of carbon dioxide.

$2 \mathrm{HCl}+\mathrm{CaCO}_{3} \rightarrow \mathrm{CaCl}_{2}+\mathrm{H}_{2} \mathrm{O}+\mathrm{CO}_{2} \uparrow$

Finally, the soluble salt is separated through filtration followed by washing with deionized water. However, the colorless product can be achieved through decolorization and bleaching with "chloroform: methanol: water $(1: 2: 4)$ " at $25^{\circ} \mathrm{C}$.

Purity of chitin, assessed through degree of acetylation, molecular mass and polydispersity, is an important concern of chitin extraction. Harsh acidic and alkaline treatments as well as increased temperature range badly affect the quality of chitin structure and function. In addition, excess usage of mineral acids and alkali cause environmental nuisance and the process is time and energy consuming.

\subsection{Biological Extraction}

Hazards associated with the chemical extraction process can be overcome through biological extraction process [9]. Biological extraction process utilizes the combination of chemical process along with biological methods such as usage of microorganisms to the system. Enzymatic deproteinization and fermentation (lactic or non-lactic) are the two most common biological methods.

\subsubsection{Enzymatic deproteinization of chitin}

Proteolytic enzymes (proteases), obtained from plant, microbial and animal sources are used for enzymatic deproteinization of chitin [10]. The mostly used proteases for chitin extraction are chymotrypsin, papain, trypsin, alkalase, devolvase, pepsin, and pancreatin [10]. Depending on the source of chitin and the enzyme utilized, deproteinization yield varies. Some of these enzymes also aid in deacetylation process [10]. One drawback of this method is that the enzymes are expensive. 


\subsubsection{Bacterial fermentation of chitin}

This is relatively an inexpensive method where the cost of using enzymes is decreased. This method is mainly performed when chitin is extracted from sea food wastes [11-12]. The fermentation is attained by adding selected strains of microorganisms or endogenous microorganisms [11$12]$. It can be with or without lactic acid bacteria capable of following one-stage and two-stage fermentation, co-fermentation/subsequent fermentation, or from endogenous microorganisms (auto-fermentation) [11-12].

\subsubsection{Lactic acid bacterial fermentation}

Lactic acid bacteria have the ability to ferment waste materials and simultaneously produce organic acids in situ (lactic and acetic acids) [1314]. Lactic acid induces precipitation of chitin and production of calcium lactate after reaction with calcium carbonate [13-14]. This action of lactic acids separates the two fractions obtained during fermentation: the liquid fraction (containing high amount of proteins, minerals and pigments) and the solid phase (containing crude chitin) [13-14]. Crude chitin can be separated by filtration and washed with water. Lactic acid is obtained by its conversion into glucose (the lowered $\mathrm{pH}$ activates the proteases and suppresses the growth of spoilage microorganisms). However, the efficiency of lactic acid fermentation relies on many factors such as the species and quantity of inoculums, carbon source and its concentration, initial $\mathrm{pH}$ and $\mathrm{pH}$ evolution during fermentation, temperature and the duration of fermentation. The frequently used bacterial strains for fermentation are Lactobacillus sp. strain especially $L$. plantarum, $L$. paracasei and L. helveticus [11-14].

\subsubsection{Non-lactic acid bacterial fermentation}

Mostly used non-lactic acid bacteria for chitin extraction are Bacillus sp., Aspergillus sp. and Pseudomonas sp., Bacillus sp. and Aspergillus sp [5].

\section{Chitin applications}

Special characteristics of chitin including biodegradability, biocompatibility and non-toxicity has enabled chitin a wide range of applications in food industry, biomedicine, environmental management, textile industry and cosmetics etc. Some of the application areas have been described below:

\subsection{Food industry}

Antioxidant and antimicrobial activity of chitin allows it to be used in the food industry to improve nutritional quality of food, maintain food safety and to extend the shelf life of food [15-20]. Chitosan is used as a food additive to enhance food taste and flavor [15]. It is also a carrier film for the antimicrobial agents [16-20]. Chitosan has applications as an emulsifier, flocculant and dietary supplement [21]. It is beneficial in making stable emulsions without any other surfactant [21]. Chitin can be used as a weight loss agent as it is a good source of dietary fiber [22]. Cationic nature of chitosan enables it to bind to cholesterol and to reduce intestinal cholesterol absorption and act as cholesterol lowering agent [2223]. In the same fashion, it lowers the level of saturated fatty acids that lowers the "saturated to unsaturated fatty acid ratio" and ameliorates the atherogenic lipid profile and hypertension [23-24]. As a prebiotic, chitosan aids in maintaining gut flora, viscosity and fermentative milieu [25-26]. Chitosan has a higher sedimentation rate, and thus, is a good flocculent in the purification system of drinking water and beverage production plants [27]. It is also used in cleansing steps of preserving fruit juices, fruits, grape wines and beer [28-29].

\subsection{Agriculture}

Chitin acts as soil modifier by enhancing soil quality, plant growth, and plant resilience [30].

Content of nitrogen in chitin and chitosan make them a rich bio-fertilizer [31]. As a bio-pesticide, chitin kills root-feeding nematodes and their eggs, as well as pathogenic fungi in the root zone [31-33]. As an elicitor of signal transduction, chitin takes part in the plant defense mechanism [34]. During fungal infection, chitin present in the fungal cell walls are degraded by plant cells' chitinase into chitin fragments (chitooligosaccharides) [34-35]. Chito-oligosaccharides participate in further protective action of plants against invaders [36]. Chitin and chitosan has important roles in seed and leaf coating [37]. They increase the seed germination rates as chitosan coating changes the permeability of seed plasma membrane and increase the enzymatic activities [37].

\subsection{Environmatel hazard mitigation plants}

As chitosan is a good adsorbent of heavy and radioactive material, its usage in waste water treatment plant, for detoxifying water bodies and removal of different dyes seem promising [38-41]. It is an efficient removal agent for metal ions such as copper, chromium, cadmium, lead, nickel, iron and arsenic [42-43].

\subsection{Biomedical and Pharmaceutical Industries}

Chitin and chitosan have been incorporated in numerous biomedical and pharmaceutical applications [44-45]. It acts as a homeostatic agent. It accelerates wound healing and dermal regeneration. As a hypocholesterolemic agent, chitosan has received seminal attention [23, 45]. Similar aspect had been noted for its anti-tumor effects [46]. Improved anti-cancer effects of some anti-cancer agents have been observed when chitin or chitosan derivatives had been used as conjugates or as adjuvants [46-48]. These combined therapies showed better anticancer effects with reduced side effects and gradual release of free drug in the cancer tissues [46-48]. As drug delivery agent, chitin and chitosan have received widespred applicability in the pharmaceutical industries [49-50]. Their muco-adhesive properties enable their carrier capacity as film, gel and powder. They are also of choice in nanotechnological application [44]. High stability, low toxicity and simple preparation method have made the chitosan nanoparticles efficient drug carriers [51].

\subsection{Biotechnological sectors}

In biotechnological plants, usage of chitin and chitosan in tissue engineering is widely performed nowadays [52]. Deaminated chitin affinity chromatography is used for the isolation, purification and concentration of lysozyme from food or biological tissues [53-54]. Productions of chitin based biosensors seem promising [55]. Chitin films and nanoparticles are ideal supports in enzyme immobilization [56]. Operational stability of chitosan-immobilized enzymes is high [57]. Bacteria-immobilized chitin flakes have been used for bioremediation of crude oil polluted sea water [58]. Chitin-based hydrogel is another biotechnological product of public importance [59].

\section{Future aspects of chitin and chitosan}

\subsection{Chitin for neurodegenerative disease amelioration}

Neurodegenerative diseases (NDs) like Alzheimer's disease (AD), Parkinson's disease (PD), and Huntington's disease (HD) have been causing immense sufferings to the humanity. No treatment is available to fully cure these diseases. Thus, search for their natural therapeutic agents have got momentum. Chitosan oligosaccharides (COs) have been found to be protective against amyloid beta $(\mathrm{A} \beta) 1-42$ induced memory and learning deficits [60]. $\mathrm{A} \beta$ fibriliogenesis is an important reason in $\mathrm{AD}$ pathogenesis. COs have been implicated in the anti-fibriliogenesis and fibriliogenesis destabilizing effect [61-62]. Neuroprotective role of COs 
is accelerated through anti-oxidative mode [63]. Also, their role against the release of pro-inflammatory cytokines would aid in $\mathrm{AD}$ amelioration [64]. Besides, acetylcholine esterase inhibitory and anti-apoptic effects of chitin derivatives have been reported to be protective against AD [65]. Additionally, chitosan based nanoparticles seemed promising as AD drug delivery agents [66]. Dysregulated apoptosis, mitochondrial membrane potential disruption, increased lactate dehydrogenase activity and reactive oxygen species generation have been implicated in PD pathogenesis [67]. Antioxidative role of chitosan and $\mathrm{CO}$ enable their therapeutic usage against PD $[64,68]$. Free-radical scavenging mode of action potentiates their usage in PD therapeutics [69].

\subsection{Probable role of chitin in coronavirus diseases}

Chitosan derivatives of low molecular weight (2-17 KDa), obtained through chemical hydrolysis, had been reported having anti-viral effects against tobacco mosaic virus (TMV), tomato yellow leaf curl virus, coliphages T2, T4 and T7 and HIV-1 [70-73]. Severe acute respiratory syndrome coronavirus-2 (SARS-CoV-2), the causative agent of the coronavirus disease 2019 (COVID-19) binds through the receptor binding domain $(\mathrm{RBD})$ of its spike protein with the angiotensin converting enzyme 2 (ACE2) receptor of the host cell [74]. Search for agents inhibiting this binding and entry into host cell have received momentum. Molecular dynamics study revealed strong binding affinity of chitosan with the RBD of SARS-CoV-2 [75]. More importantly, $\beta$-chitosan had been found effective in inhibiting the binding of SARS-CoV-2 with the ACE2 receptor. Even downregulated production of ACE2 receptor in vero E6 cells had been linked with chitosan [76]. Chitosan nanoparticles have been found effective anti-viral drug delivery agents [77]. Chitosan naoparticles and nanofibers seem to be of utmost usage in delivering COVID-19 drugs [78]. Besides, innate immunity boosting effects of chitin microparticles substantiate their usage against SARS-CoV-2 [79]. Recently, possibility of chitosan-coated DNA vaccine against SARS-Co$\mathrm{V}-2$ has been conceptualized [80].

\section{Conclusion}

Chitin is a natural polysaccharide of immense importance. Food, biomedicine, nanotechnology and environmental aspects of this natural biopolymer beacons its extensive utilization for the betterment of the human being. Application of chitin in withstanding the progression of the pandemic COVID-19 would be of its most-immediate utilization. Thus, less expensive, eco-friendly and quick extraction process of chitin along with much extensive research is called for.

\section{Funding:}

No funding has been received to conduct this study.

\section{Conflict of Interest:}

Authors declare no conflict of interest.

\section{Reference}

1. Jeuniaux C. (1996) A brief survey of the early contribution of European scientists to chitin knowledge. In: Domard A, Jeuniaux C, Muzzarelli RAA, Roberts G, editors. Advances in Chitin Sciences. Jacques André Publ; Lyon, France: pp. 1-9.

2. Jollès P, Muzzarelli RAA. (1999) Chitin and Chitinases. Birkhäuser Verlag; Basel, Switzerland.

3. Einbu A, Vårum KM. (2008) Characterization of chitin and its hydrolysis to GlcNAc and GlcN. Biomacromolecules. 9(7):18705. doi: 10.1021/bm8001123. Epub 2008 Jun 10. PMID: 18540645.

4. Zhang E, Xing R, Liu S, Qin Y, Li K, Li P. (2019) Advances in chitosan-based nanoparticles for oncotherapy. Carbohydr Polym.
222: 115004. doi: 10.1016/j.carbpol.2019.115004. Epub 2019 Jun 19. PMID: 31320066.

5. Khoushab F, Yamabhai M. (2010) Chitin research revisited. Mar Drugs. 8(7):1988-2012. doi: 10.3390/md8071988. PMID: 20714419; PMCID: PMC2920538.

6. Younes I, Rinaudo M. (2015) Chitin and chitosan preparation from marine sources. Structure, properties and applications. Mar Drugs. 13(3):1133-74. doi: 10.3390/md13031133. PMID: 25738328; PMCID: PMC4377977.

7. Muxika A, Etxabide A, Uranga J, Guerrero P, de la Caba K. (2017) Chitosan as a bioactive polymer: Processing, properties and applications. Int J Biol Macromol. 105(Pt 2):1358-1368. doi: 10.1016/j.ijbiomac.2017.07.087. Epub 2017 Jul 20. PMID: 28735006.

8. Mohan K, Ganesan AR, Muralisankar T, Jayakumar R, Sathishkumar P, et al. (2020) Recent insights into the extraction, characterization, and bioactivities of chitin and chitosan from insects. Trends Food Sci Technol. 105:17-42. doi: 10.1016/j.tifs.2020.08.016. Epub 2020 Sep 4. PMID: 32901176; PMCID: PMC7471941.

9. Kaur S, Dhillon GS. (2015) Recent trends in biological extraction of chitin from marine shell wastes: a review. Crit Rev Biotechnol. 35(1):44-61. doi: 10.3109/07388551.2013.798256. Epub 2013 Oct 1. PMID: 24083454.

10. Jantzen da Silva Lucas A, Quadro Oreste E, Leão Gouveia Costa H, Martín López H, Dias Medeiros Saad C, Prentice C. (2021) Extraction, physicochemical characterization, and morphological properties of chitin and chitosan from cuticles of edible insects. Food Chem. 343:128550. doi: 10.1016/j.foodchem.2020.128550. Epub 2020 Nov 6. PMID: 33191008.

11. Arbia W., Arbia L., Adour L., Amrane A. (2013) Chitin extraction from crustacean shells using biological methodsA review. Food Technol. Biotechnol. 51:12-25.

12. Castro R., Guerrero-Legarreta I., Bórquez R. (2018) Chitin extraction from allopetrolisthes punctatus crab using lactic fermentation. Biotechnol. Rep. e00287. doi: 10.1016/j.btre.2018.e00287.

13. Liu Y, Xing R, Yang H, Liu S, Qin Y, Li K, Yu H, Li P. (2020) Chitin extraction from shrimp (Litopenaeus vannamei) shells by successive two-step fermentation with Lactobacillus rhamnoides and Bacillus amyloliquefaciens. Int J Biol Macromol. 148:424433. doi: 10.1016/j.ijbiomac.2020.01.124. Epub 2020 Jan 15. PMID: 31954122.

14. Sedaghat F, Yousefzadi M, Toiserkani H, Najafipour S. (2017) Bioconversion of shrimp waste Penaeus merguiensis using lactic acid fermentation: An alternative procedure for chemical extraction of chitin and chitosan. Int J Biol Macromol. 104(Pt A):883-888. doi: 10.1016/j.ijbiomac.2017.06.099. Epub 2017 Jun 27. PMID: 28663153.

15. Je J-Y, Kim S-K. (2006) Antioxidant activity of novel chitin derivative. Bioorg. Med. Chem. Lett. 16:1884-1887

16. Wang W, Meng Q, Li Q, Liu J, Zhou M, Jin Z, Zhao K. (2020) Chitosan Derivatives and Their Application in Biomedicine. Int J Mol Sci. 21(2):487. doi: 10.3390/ijms21020487. PMID: 31940963; PMCID: PMC7014278.

17. Bautista-Baños S, Hernández-López M, Bosquez-Molina E, Wilson CL. (2003) Effects of chitosan and plant extracts on growth of Colletotrichum gloeosporioides, anthracnose levels and quality of papaya fruit. Crop. Prot. 22:1087-1092.

18. Tsai GJ, Su WH. (1999) Antibacterial activity of shrimp chitosan against Escherichia coli. J. Food Prot. 62:239-243.

19. San-Lang W, Shih I-L, Wang C-H, Tseng K-C, Chang et al. (2002) Production of antifungal compounds from chitin by Bacillus subtilis. Enzyme Microb. Technol. 31:321-328. 
20. Li B, Wang X, Chen R, Huangfu W, Xie G. (2008) Antibacterial activity of chitosan solution against Xanthomonas pathogenic bacteria isolated from Euphorbia pulcherrima. Carbohydr. Polym. 72:287-292.

21. Utai Klinkesorn (2013) The Role of Chitosan in Emulsion Formation and Stabilization, Food Reviews International, 29:4, 371393, DOI: $10.1080 / 87559129.2013 .818013$.

22. Mhurchu CN, Poppitt SD, McGill AT, Leahy FE, Bennett DA, et al. (2004) The effect of the dietary supplement, Chitosan, on body weight: a randomised controlled trial in 250 overweight and obese adults. Int J Obes Relat Metab Disord. 28(9):1149-56. doi: 10.1038/sj.ijo.0802693. PMID: 15311218.

23. Hossain S, Rahman A, Kabir Y, Shams AA, Afros F, Hashimoto M. (2007) Effects of shrimp (Macrobracium rosenbergii)-derived chitosan on plasma lipid profile and liver lipid peroxide levels in normo- and hypercholesterolaemic rats. Clin Exp Pharmacol Physiol. 34(3):170-6. doi: 10.1111/j.1440-1681.2007.04568.x. PMID: 17250635.

24. Huang H, Zou Y, Chi H. (2017) Quantitative assessment of the effects of chitosan intervention on blood pressure control. Drug Des Devel Ther. 12:67-75. Published 2017 Dec 28. doi:10.2147/DDDT.S148064.

25. Albadran HA, Monteagudo-Mera A, Khutoryanskiy VV, Charalampopoulos D. (2020) Development of chitosan-coated agar-gelatin particles for probiotic delivery and targeted release in the gastrointestinal tract. Appl Microbiol Biotechnol. 104(13):5749-5757. doi: 10.1007/s00253-020-10632-w. Epub 2020 May 6. PMID: 32377900; PMCID: PMC7306021.

26. Yang L, Han Z, Chen C, Li Z, Yu S, Qu Y, Zeng R. (2020) Novel probiotic-bound oxidized Bletilla striata polysaccharide-chitosan composite hydrogel. Mater Sci Eng C Mater Biol Appl. 117:111265. doi: 10.1016/j.msec.2020.111265. Epub 2020 Jul 6. PMID: 32919631.

27. Qu B, Luo Y. (2020) Chitosan-based hydrogel beads: Preparations, modifications and applications in food and agriculture sectors - A review. Int J Biol Macromol. 152:437-448. doi: 10.1016/j.ijbiomac.2020.02.240. Epub 2020 Feb 22. PMID: 32097742 .

28. A. Bhatnagar, M. Sillanpää, (2009) Applications of chitinand chito- san-derivatives for the detoxification of water and waste- water - A short review, Adv. Colloid Interface Sci. 152, 26-38.

29. Rocha, M. A. M., Coimbra, M. A., Nunes, C. (2017) Applications of chitosan and their derivatives in beverages: a critical review. Current Opinion in Food Science, 15, 6169. https://doi.org/10.1016/j.cofs.2017.06.008

30. Boukhlifi Fatima, Mamouni Fatima Zahrae and R. Razouk (2018). Chitin/Chitosan's Bio-Fertilizer: Usage in Vegetative Growth of Wheat and Potato Crops, Chitin-Chitosan - Myriad Functionalities in Science and Technology, Rajendra Sukhadeorao Dongre, IntechOpen, DOI: 10.5772/intechopen.75208.

31. E. Ait Barka, P. Eullaffroy, C. Clément, G. Vernet, (2004) Chitosan improves development, and protects Vitis vinifera L. against Botrytis cinerea, Plant Cell Rep. 22 608-614.

32. W. San-Lang, I.L. Shih, C.H. Wang, K.C. Tseng, W.T. Chang,Y.K. Twu et al., (2002) Production of antifungal compounds from chitin by Bacillus subtilis, Enzyme Microb. Technol. 31 321-328.

33. Tanaka K, Nguyen CT, Liang Y, Cao Y, Stacey G. (2013) Role of LysM receptors in chitin-triggered plant innate immunity. Plant Signal Behav. 8(1):e22598. doi: 10.4161/psb.22598. Epub 2012 Dec 6. PMID: 23221760; PMCID: PMC3745565.
34. Kaku H, Nishizawa Y, Ishii-Minami N, Akimoto-Tomiyama C, Dohmae N, et al. (2006) Plant cells recognize chitin fragments for defense signaling through a plasma membrane receptor. Proc Natl Acad Sci $U$ S A. 103(29):11086-91. doi: 10.1073/pnas.0508882103. Epub 2006 Jul 7. PMID: 16829581; PMCID: PMC1636686.

35. Garcia TB, Soares AA, Costa JH, Costa HPS, Neto JXS, et al. (2019) Gene expression and spatiotemporal localization of antifungal chitin-binding proteins during Moringa oleifera seed development and germination. Planta. 249(5):1503-1519. doi: 10.1007/s00425-019-03103-8. Epub 2019 Jan 31. PMID: 30706136.

36. Lan W, Wang W, Yu Z, Qin Y, Luan J, Li X. (2016) Enhanced germination of barley (Hordeum vulgare L.) using chitooligosaccharide as an elicitor in seed priming to improve malt quality. Biotechnol Lett. 38(11):1935-1940. doi: 10.1007/s10529016-2181-5. Epub 2016 Jul 27. PMID: 27465671.

37. Guan YJ, Hu J, Wang XJ, Shao CX. (2009) Seed priming with chitosan improves maize germination and seedling growth in relation to physiological changes under low temperature stress. J Zhejiang Univ Sci B. (6):427-33. doi: 10.1631/jzus.B0820373. PMID: 19489108; PMCID: PMC2689555.

38. Yang R, Li H, Huang M, Yang H, Li A. (2016) A review on chitosan-based flocculants and their applications in water treatment. Water Res. 95:59-89. doi: 10.1016/j.watres.2016.02.068. Epub 2016 Mar 3. PMID: 26986497.

39. O.S. Amuda, A.A. Giwa, I. Bello, (2007) Removal of heavy metal from industrial wastewater using modified activated coco- nut shell carbon, Biochemical Eng. J. 36 174-181.

40. K.D. Trimukhe, A.J. Varma, (2008) Complexation of heavy metals by crosslinked chitin and its deacetylated derivatives, Car-bohydr. Polym. 71, 66-73.

41. Akkaya, I. Uzun, F. Güzel, (2009) Adsorption of some highly toxic dyestuffs from aqueous solution by chitin and its synthesized derivatives, Desalination, 249, 1115-1123

42. Khan SA, Khan SB, Kamal T, Asiri AM, Akhtar K. (2016) Recent Development of Chitosan Nanocomposites for Environmental Applications. Recent Pat Nanotechnol. 10(3):181-188. doi: 10.2174/1872210510666160429145339. PMID: 27136929.

43. Fan Y, Ginn A, Ma Z, Kang M, Jeong KC, Wright AC. (2017) Application of chitosan microparticles for mitigation of Salmonella in agricultural water. J Appl Microbiol. 123(5):13461358. doi: 10.1111/jam.13566. Epub 2017 Oct 6. PMID: 28815882.

44. Wang W, Meng Q, Li Q, Liu J, Zhou M, Jin Z, Zhao K. (2020) Chitosan Derivatives and Their Application in Biomedicine. Int J Mol Sci. 21(2):487. doi: 10.3390/ijms21020487. PMID: 31940963 ; PMCID: PMC7014278.

45. Satitsri S, Muanprasat C. (2020) Chitin and Chitosan Derivatives as Biomaterial Resources for Biological and Biomedical Applications. Molecules. 25(24):5961.

46. Zhang E, Xing R, Liu S, Qin Y, Li K, Li P. (2019) Advances in chitosan-based nanoparticles for oncotherapy. Carbohydr Polym. 222:115004. doi: 10.1016/j.carbpol.2019.115004. Epub 2019 Jun 19. PMID: 31320066.

47. Chi J, Jiang Z, Qiao J, Peng Y, Liu W, Han B. (2019) Synthesis and anti-metastasis activities of norcantharidin-conjugated carboxymethyl chitosan as a novel drug delivery system. Carbohydr Polym. 214:80-89. doi: 10.1016/j.carbpol.2019.03.026. Epub 2019 Mar 11. PMID: 30926011.

48. Zhang W, Feng J. (2020) Multi-functional chitosan polymeric micelles as oral paclitaxel delivery systems for enhanced 
bioavailability and anti-tumor efficacy. Int J Pharm. 578:119105. doi: 10.1016/j.ijpharm.2020.119105. Epub 2020 Feb 1. PMID: 32018019.

49. Ahmed TA, Aljaeid BM. Preparation, (2016) characterization, and potential application of chitosan, chitosan derivatives, and chitosan metal nanoparticles in pharmaceutical drug delivery. Drug Des Devel Ther. 10:483-507. doi: 10.2147/DDDT.S99651. PMID: 26869768; PMCID: PMC4734734.

50. Babu A, Ramesh R. (2017) Multifaceted Applications of Chitosan in Cancer Drug Delivery and Therapy. Mar Drugs. 15(4):96. doi: 10.3390/md15040096. PMID: 28346381; PMCID: PMC5408242.

51. Riaz Rajoka MS, Zhao L, Mehwish HM, Wu Y, Mahmood S. (2019) Chitosan and its derivatives: synthesis, biotechnological applications, and future challenges. Appl Microbiol Biotechnol. 103(4):1557-1571. doi: 10.1007/s00253-018-9550-z. Epub 2019 Jan 3. PMID: 30607489.

52. Sukhoverkov KV, Kudryashova EV. (2015) PEG-chitosan and glycol-chitosan for improvement of biopharmaceutical properties of recombinant L-asparaginase from Erwinia carotovora. Biochemistry (Mosc). 80(1):113-9. doi: 10.1134/S0006297915010137. PMID: 25754046.

53. Muzzarelli RA, Barontini G, Rocchetti R. (1978) Isolation of lysozyme on chitosan. Biotechnol Bioeng. 20(1):87-94. doi: 10.1002/bit.260200107. PMID: 23877.

54. Hirsch DB, Baieli MF, Urtasun N, Lázaro-Martínez JM, Glisoni RJ, Miranda MV, Cascone O, Wolman FJ. (2018) Sulfanilic acidmodified chitosan mini-spheres and their application for lysozyme purification from egg white. Biotechnol Prog. 34(2):387-396. doi: 10.1002/btpr.2588. Epub 2017 Dec 7. PMID: 29193855.

55. Rezaei B, Jamei HR, Ensafi AA. (2018) An ultrasensitive and selective electrochemical aptasensor based on rGOMWCNTs/Chitosan/carbon quantum dot for the detection of lysozyme. Biosens Bioelectron. 115:37-44. doi: 10.1016/j.bios.2018.05.012. Epub 2018 May 9. PMID: 29793133.

56. Wang D, Jiang W. (2019) Preparation of chitosan-based nanoparticles for enzyme immobilization. Int J Biol Macromol. 126:1125-1132. doi: 10.1016/j.ijbiomac.2018.12.243. Epub 2018 Dec 27. PMID: 30594622.

57. Yeon KM, You J, Adhikari MD, Hong SG, Lee I, Kim HS, Kim LN, Nam J, Kwon SJ, Kim MI, Sajomsang W, Dordick JS, Kim J. (2019) Enzyme-Immobilized Chitosan Nanoparticles as Environmentally Friendly and Highly Effective Antimicrobial Agents. Biomacromolecules. 20(7):2477-2485. doi: 10.1021/acs.biomac.9b00152. Epub 2019 May 16. PMID: 31094205.

58. Zhang S, Lu F, Tao L, Liu N, Gao C, Feng L, Wei Y. (2013) Bioinspired anti-oil-fouling chitosan-coated mesh for oil/water separation suitable for broad $\mathrm{pH}$ range and hyper-saline environments. ACS Appl Mater Interfaces. 5(22):11971-6. doi: 10.1021/am403203q. Epub 2013 Nov 11. PMID: 24180691.

59. Deng XQ, Chao NN, Ding W, Qin TW, Wang W, Zhang Y, Luo JC. (2019) Production and Characterization of Composite Chitosan Hydrogel Containing Extracellular Matrix Particles for Tissue Engineering Applications. J Biomed Nanotechnol. 15(4):756-768. doi: 10.1166/jbn.2019.2713. PMID: 30841968.

60. Jia S, Lu Z, Gao Z, An J, Wu X, Li X, Dai X, Zheng Q, Sun Y. (2016) Chitosan oligosaccharides alleviate cognitive deficits in an amyloid- $\beta 1-42$-induced rat model of Alzheimer's disease. Int $J$ Biol Macromol. 83:416-25. doi: 10.1016/j.ijbiomac.2015.11.011. Epub 2015 Nov 18. PMID: 26601759.

61. Dai X, Chang P, Zhu Q, Liu W, Sun Y, Zhu S, Jiang Z. (2013) Chitosan oligosaccharides protect rat primary hippocampal neurons from oligomeric $\beta$-amyloid 1-42-induced neurotoxicity.
Neurosci Lett. 554:64-9. doi: 10.1016/j.neulet.2013.08.046. Epub 2013 Aug 30. PMID: 23999027.

62. Zhou S, Yang Y, Gu X, Ding F. (2008) Chitooligosaccharides protect cultured hippocampal neurons against glutamate-induced neurotoxicity. Neurosci Lett. 444(3):270-4. doi: 10.1016/j.neulet.2008.08.040. Epub 2008 Aug 19. PMID: 18755243.

63. Nidheesh T, Salim C, Rajini PS, Suresh PV. (2015) Antioxidant and neuroprotective potential of chitooligomers in Caenorhabditis elegans exposed to Monocrotophos. Carbohydr Polym. 135:13844. doi: 10.1016/j.carbpol.2015.08.055. Epub 2015 Aug 21. PMID: 26453861.

64. Hao C, Wang W, Wang S, Zhang L, Guo Y. (2017) An Overview of the Protective Effects of Chitosan and Acetylated Chitosan Oligosaccharides against Neuronal Disorders. Mar Drugs. 15(4):89. doi: 10.3390/md15040089. PMID: 28333077; PMCID: PMC5408235.

65. Lee SH, Park JS, Kim SK, Ahn CB, Je JY. (2009) Chitooligosaccharides suppress the level of protein expression and acetylcholinesterase activity induced by Abeta25-35 in PC12 cells. Bioorg Med Chem Lett. 19(3):860-2. doi: 10.1016/j.bmcl.2008.12.019. Epub 2008 Dec 10. PMID: 19097785.

66. Manek E, Petroianu GA. (2021) Chitosan-based nanoparticles in Alzheimer's disease: messenger or message? Neural Regen Res. 16(11):2204-2205. doi: 10.4103/1673-5374.310685. PMID: 33818494.

67. Bose A, Beal MF. (2016) Mitochondrial dysfunction in Parkinson's disease. J Neurochem. 139 Suppl 1:216-231. doi: 10.1111/jnc.13731. Epub 2016 Aug 21. PMID: 27546335.

68. Wang X, Miao J, Yan C, Ge R, Liang T, Liu E, Li Q. (2016) Chitosan attenuates dibutyltin-induced apoptosis in PC12 cells through inhibition of the mitochondria-dependent pathway. Carbohydr Polym. 151:996-1005. doi: 10.1016/j.carbpol.2016.06.053. Epub 2016 Jun 15. PMID: 27474647.

69. Xu W, Huang HC, Lin CJ, Jiang ZF. (2010) Chitooligosaccharides protect rat cortical neurons against copper induced damage by attenuating intracellular level of reactive oxygen species. Bioorg Med Chem Lett. 20(10):3084-8. doi: 10.1016/j.bmcl.2010.03.105. Epub 2010 Apr 2. PMID: 20399653.

70. Davydova VN, Nagorskaia VP, Gorbach VI, Kalitnik AA, Reunov AV, Solov'eva TF, Ermak IM. (2011) Chitosan antiviral activity: dependence on structure and depolymerization method. Prikl Biokhim Mikrobiol. 47(1):113-8. Russian. PMID: 21442928.

71. Y. Hu, J. Cai, Y. Du, J. Lin, C. Wang, K. Xiong, (2009) Preparation and anti-TMV activity of guanidinylated chitosan hydrochloride, J. Appl. Polym. Sci. 112 (6) 3522-3528.

72. N. Noiket, T. Boonthip, K. Riangwong, (2014) Evaluation of potential for chitosan to control TYLCV disease and promote the growth of Sridathip 3 tomato, Thai Society for Biotechnology, Electronic Proceeding of the 26th Annual Meeting of the Thai Society for Bio-technology and International Conference Mae Fah Luang University Chiang Rai Thailand, pp. 252-259.

73. R. Jayakumar, N. Nwe, S. Tokura, H. (2007) Tamura, Sulfated chitin and chitosan as novel biomaterials, Int. J. Biol. Macromol. 40 (3), 175-181.

74. Rahman MA, Islam K, Rahman S, Alamin M. (2021) Neurobiochemical Cross-talk Between COVID-19 and Alzheimer's Disease. Mol Neurobiol. 58(3):1017-1023. doi: 10.1007/s12035-020-02177-w. Epub 2020 Oct 19. PMID: 33078369; PMCID: PMC7571527.

75. Kalathiya U, Padariya M, Mayordomo M, Lisowska M, Nicholson J, et al. (2020) Highly Conserved Homotrimer Cavity Formed by 
the SARS-CoV-2 Spike Glycoprotein: A Novel Binding Site. $J$ Clin Med. 9(5):1473. doi: 10.3390/jcm9051473. PMID: 32422996; PMCID: PMC7290299.

76. G. Alitongbieke, X.-M. Li, Q.-C. Wu, Z.-C. Lin, J.-F. Huang, Y. Xue, et al., (2020) Effect of $\beta$ - Chitosan on the Binding Interaction between SARS-CoV-2 S-RBD and ACE2. bioRxiv.

77. R. Davis, S. Zivanovic, (2012) Effectiveness of chitosan on the inactivation of enteric viral surrogates, Food Microbiol. 32 (1), $57-62$.

78. Hathout RM, Kassem DH. (2020) Positively Charged Electroceutical Spun Chitosan Nanofibers Can Protect Health Care Providers From COVID-19 Infection: An Opinion. Front Bioeng Biotechnol. 8:885. doi: 10.3389/fbioe.2020.00885. PMID: 32974290 ; PMCID: PMC7461847.
79. Mami S, Yeganeh F, Salari AA, Anissian A, Azizi M, Hajimollahoseini M. (2020) Oral chitin treatment improved demyelination in murine autoimmune encephalomyelitis model by inhibition of inflammatory responses. Int Immunopharmacol. 106536. doi: 10.1016/j.intimp.2020.106536. Epub 2020 Apr 30. PMID: 32361654.

80. Tatlow D, Tatlow C, Tatlow S, Tatlow S. (2020) A novel concept for treatment and vaccination against Covid-19 with an inhaled chitosan-coated DNA vaccine encoding a secreted spike protein portion. Clin Exp Pharmacol Physiol. 47(11):1874-1878. doi: 10.1111/1440-1681.13393. Epub 2020 Sep 10. PMID: 32881059; PMCID: PMC7436441. (c) (7)

This work is licensed under Creative Commons Attribution 4.0 License

To Submit Your Article Click Here: Submit Manuscript

DOI: $10.31579 / 2766-2314 / 056$
Ready to submit your research? Choose Auctores and benefit from:

$>$ fast, convenient online submission

$>$ rigorous peer review by experienced research in your field

$>$ rapid publication on acceptance

$>$ authors retain copyrights

$>$ unique DOI for all articles

$>$ immediate, unrestricted online access

At Auctores, research is always in progress.

Learn more auctoresonline.org/journals/biotechnology-andbioprocessing 